REVISTA DE DERECHO UNED, NÚM. 22, 2018

\title{
MARCO LEGISLATIVO QUE REGULA LA ACTUACIÓN EN LOS CENTROS DE INTERNAMIENTO DE MENORES INFRACTORES EN ANDALUCÍA (ESPAÑA). RECORRIDO HISTÓRICO Y DESARROLLO ACTUAL
}

\author{
REGULATORY FRAMEWORK FOR JUVENILE PRISON \\ PRACTICES IN ANDALUCÍA (SPAIN). AN HISTORIC APPROACH \\ AND CURRENT CONTENTS
}

IGNACIO ALCALDE

Profesor de Antropología Social. Universidad de Córdoba

Resumen: En este artículo se realiza un recorrido por toda la legislación que actúa en relación a los menores infractores y los centros de internamiento destinados al cumplimiento de sus medidas judiciales. Con una perspectiva histórica, desde su aparición específica en el ámbito internacional hasta el marco autonómico andaluz, en España, pasando por las principales normas europeas y estatales; exponemos todo el marco normativo, haciendo un análisis especial de las leyes vigentes en la actualidad.

Palabras clave: Menores infractores, internamiento, centro de menores.

Abstract: This article shows the main aspects of the whole legislation about juvenile offenders and young prisons. With a historic approach, from their specific birth in the international court, to local approach (Andalusia), including the European and Spanish development; we present an exposition of the whole rule frame, making a special analysis of the current laws. 
Keywords: juvenile offenders, internment, young prison, juvenile prison.

Recepción original: 15/11/2017

Aceptación original: 12/02/2018

Sumario: I. Marco internacional. II. Marco europeo III. Marco español IV. Marco autonómico V. Algunas conclusiones

El ejemplo tiene más fuerza que las reglas.

N. Gogol. Almas muertas.

En este artículo mostramos toda la normativa que actúa en los Centros de Internamiento de Menores Infractores en la comunidad autónoma de Andalucía, dentro del estado español. Haremos por tanto una exposición sobre el recorrido histórico de estas normas para, finalmente, analizar sus principales planteamientos y contenidos en la actualidad. Planteamientos formales que serán los principales marcos de referencia y el paraguas bajo el que se fundamente toda la actuación que se lleva a cabo en estos centros, por lo que resultan imprescindibles para la comprensión de estas instituciones.

Para ello, haremos un recorrido por toda la legislación en este ámbito y describiremos brevemente su origen y fundamentación, lo haremos de manera concéntrica y desde una perspectiva histórica, partiendo desde el marco internacional, continuando con la normativa de carácter europeo, la legislación estatal y, finalmente, la procedente de la comunidad autónoma andaluza.

De esta forma, mostraremos un mosaico general con el que entender toda la normativa que rige la actuación sobre los menores. Cómo se ha articulado, su proveniencia y la situación actual. Un artículo que, creemos, de enrome utilidad para formar una idea integral del devenir legislativo y su situación actual.

\section{MARCO INTERNACIONAL}

De forma introductoria y simplemente para fijar un par de fechas previas al siglo $\mathrm{xx}$ - que será cuando comience a desarrollarse de manera específica la legislación sobre el menor- podemos situar el germen del desarrollo jurídico moderno sobre los menores 
de edad en el siglo XviII. Al igual que ocurre con el lento despegue de la creación de instituciones particulares para su encierro, ${ }^{1}$ será aquí cuando se ponga el foco en la necesidad de una atención específica y separada de los adultos. El Siglo de las Luces marcará el comienzo de ese cambio de rumbo por el que, tanto la legislación sobre adultos como la de menores, destierre la tortura y los castigos físicos ${ }^{2}$, encaminándose hacia el carácter reeducativo y responsabilizador de los siguientes siglos. De la mano de la Ilustración, comenzará un movimiento, a caballo entre la filosofía y la pedagogía, que pondrá el foco de atención sobre la distinción de los menores y que incitaría a conocerlos mejor, destacando la infancia como una etapa con una realidad propia, diferente y definida, tal como afirmaría Rousseau.

Esta iniciación en la atención a los menores de manera exclusiva desembocará en el movimiento de salvación del niño en Chicago; por el que se funda en 1899 el primer tribunal para niños, desarrollando toda una legislación específica sobre éstos, creándose así la Children Court. ${ }^{3}$ Ésta recogerá la primera separación jurídica para menores de edad y se indicarán algunas pautas esenciales como la supresión de la

${ }^{1} \mathrm{Al}$ igual que con la legislación, respecto a la creación de centros de menores, aunque en los siglos anteriores podemos analizar el tratamiento de éstos en el Código de las Siete Partidas de Alfonso X (siglo XIII), la legislación de la mano de Pedro IV el Ceremoniosos (siglo XIV) o la progresiva creación de Hospitales, Workhouses, Casas de Oficios, Hospicios o Casas de Misericordia, no tendrán un tratamiento distinto en muchos casos de los adultos, pudiendo sufrir penas de galeras y no distinguiéndose en muchos casos entre vagabundos, desvalidos o delincuentes hasta bien avanzado el siglo XVIII. Véase Apuntes para una historia de las instituciones de menores en España, (Sánchez Vázquez y Guijarro Granados, 2002), La finalidad educativa de los Centros de Internamiento de Menores, el Hospicio como antecedente (Cámara Arroyo, 2010) o Aproximación a la Historia de las Prisiones. El caso de Málaga (Fernández Escorial, 2006).

2 «esa amalgama de castigos que se caracterizan por ser heterogéneos, caóticos, desigual, rigurosos, crueles y arbitrarios» (Monge González, 1997: 25). Este tema también aparece ampliamente desarrollado en Historia de la prisión en España (Roldán Barbero, 1988) e Historia de la Prisión: teoría economicista, crítica. (García Valdes, 1997).

${ }^{3}$ Tal como nos indica Sánchez Vázquez y Guijarro Granados (2002), en Europa habrá otros intentos similares. Cabe destacar aquí, aunque no sea el objetivo del artículo, la Casa de Toribios de Sevilla, creada en 1723 (un siglo y medio antes) y fundada con la intención de reformar el carácter y costumbres de los niños delincuentes. Suponiendo así el primer intento de centro de este tipo. Ésta, constaba de un sistema educativo, horario de actividades escolares y talleres y registro de menores y aunque desparecerá con la muerte de su fundador, supondrá el primer intento de creación de una institución particular para menores delincuentes, previa a la considerada la primera de este tipo, la George Junior Republic, que nacerá bajo esa influencia de la Children Court, de Chicago y de la que partirán todas las demás en el siglo Xx. 
cárcel para menores de 16 años, las medidas de corte educativo y la creación de otros espacios destinados a su internamiento.

De esta manera, aunque no tenían la intención de servir de marco internacional, sí que sienta algunas de los principios sobre los que se va a actuar, reformando el marco judicial e introduciendo algunos elementos; tal como la especialización del Tribunal, la edad límite en los 16 años, la supresión de la cárcel para los niños, ofreciendo alternativas como las casas de reforma, patronatos, etc., o la aparición de la libertad vigilada como medida a imponer al menor.

Estas ideas se propagaran al resto de estados de EEUU, así como a otros países que enunciarán leyes similares, como Alemania (1907), Inglaterra (1908) o Portugal (1911) que, poco a poco, comenzarán a seguir sus enunciados (Sánchez Vázquez y Guijarro Granados, 2002: 128).

Una vez en el siglo $\mathrm{xx}$, las directrices sobre la responsabilidad penal del menor y el internamiento de éste en centros con privación de libertad a nivel internacional vendrán marcadas por las diferentes declaraciones provenientes de las Naciones Unidas y su predecesora, la Sociedad de Naciones. En la mayoría de los casos, estas declaraciones tendrán un carácter no vinculante que tendrá que ser ratificado por cada país miembro.

En este sentido nos encontramos con las siguientes:

Declaración de Ginebra sobre los Derechos del Niño. Adoptada por la Sociedad de Naciones en 1924 a propuesta de Eglantyne Jebb. Dicha declaración contenía solamente cinco artículos y por primera vez, se pasaba de hablar de beneficencia a derechos sociales de los niños. Se promulgaba el derecho a su normal desarrollo, a la educación, al socorro, a la protección frente a la explotación y al deber de poner sus cualidades al servicio del prójimo.

Esta declaración desembocó en una nueva tras la Segunda Guerra Mundial, la Declaración de los Derechos del Niño de 1959, aprobada por la Asamblea General de las Naciones Unidas y ratificada por sus 78 estados miembros. Lo que supuso el primer gran consenso sobre la sensibilización acerca de la especial legislación necesaria hacia los menores de edad. Ésta consta de diez artículos, donde se destaca (tal como dice su preámbulo) que "por su falta de madurez física y mental, necesita protección y cuidado especiales, incluso la debida protección legal (...)»(Naciones Unidas. Declaración de los Derechos del Niño, 1959) 
Tras este se realizó el Segundo Congreso de las Naciones Unidas ${ }^{4}$ sobre Prevención del Delito y Tratamiento del Delincuente (Londres, del 8 al 20 de agosto de 1960), donde se recomendaron servicios especiales de policía para la justicia de menores así como herramientas para implementar la coordinación entre la policía y los diferentes organismos nacionales relacionados con los menores.

En este ámbito internacional, y destacándose el tema de los menores, se produjo el Sexto Congreso de las Naciones Unidas sobre Prevención del Delito y Tratamiento del Delincuente ( Caracas, del 5 al 20 de agosto de 1980), en el que, en su resolución cuarta, expone una elaboración de normas mínimas para la justicia en menores. En éste, se intentan describir unas directrices mínimas uniformes sobre la administración de justicia para menores así como la atención a éstos, con la intención de que sirviese de modelo para sus estados miembros. En esta resolución se destaca que debe elaborarse una protección jurídica específica para los menores que se encuentren en dificultades con la justicia, la utilización del internamiento y/o detención como último recurso y la creación de instituciones específicas sobre el tratamiento y prevención de la delincuencia de menores de edad. Este planteamiento será desarrollado en los años venideros y encargado un proyecto de cara al Séptimo Congreso de 1985 (Milán, del 26 de agosto al 6 de septiembre), lo que desembocará en las Reglas de Beijing.

Las Reglas Mínimas de la ONU para la Administración de la Justicia de Menores «Reglas de Beijing», Resolución 40/33, de 29 de noviembre de 1985. En este documento, primero en poner toda su atención en el desarrollo de una legislación específica sobre la justicia de menores a nivel internacional, se pone de manifiesto la necesidad de crear unas orientaciones fundamentales que aseguren el bienestar del menor. Se elaboran unas definiciones comunes en las que aparecen el concepto de menor como aquel sujeto que por su edad debe ser tratado penalmente de manera diferente al adulto, el concepto de delito como todo aquel acto penado por el sistema jurídico respectivo y menor delincuente como aquel niño o joven al que se le ha imputado la comisión de un delito o se le ha considerado culpable en la comisión de éste.

\footnotetext{
${ }^{4}$ Este congreso se celebra cada lustro, por lo que recientemente se ha llevado a cabo el $13^{\circ}$ Congreso en Doha del 12 al 19 de abril de 2015. A lo largo de estos años en cada uno de ellos se ha hecho hincapié en alguno de los problemas más acuciantes en ese momento. Desde el tratamiento de los reclusos, a la cooperación internacional en la prevención de delitos. Por lo que el tema de los menores ha aparecido de manera específica en varios de ellos tal como mencionamos aquí.
} 
Tras esto, se remarca la conveniencia de que cada estado miembro promulgue una legislación específica para este colectivo y que en esta se tenga en cuenta que la mayoría de edad no debe fijarse en una etapa demasiada temprana, que la respuesta legal sea proporcionada, que se cumplan las garantías procesuales básicas, el derecho de los menores a preservar su intimidad así como una serie de indicaciones sobre el procesamiento e investigación, prisión preventiva y preparación especial de la policía que trabaje con estos grupos.

En la tercera parte de estas reglas se enumeran unas indicaciones sobre el dictamen de la sentencia y su resolución así como las diferentes medidas, registros o la necesidad de personal específico y especializado.

Finalmente, en su cuarta y quinta parte nos enumera las características que deben tener la resolución de las medidas, tanto dentro de los establecimientos penitenciarios como fuera de ellos. En este mismo apartado se nos comienzan ya a indicar las características que deben tener estos centros, acercándonos a nuestro objeto de estudio y perfilando cómo deben ser los Centros de Internamiento de Menores Infractores, definiendo el objeto de estos centros penitenciarios respecto al menor interno como el de «garantizar su cuidado y protección, así como su educación y formación profesional para permitirles que desempeñen un papel constructivo y productivo en la sociedad.» De la misma forma, en este mismo apartado se indicará también que deben estar separados de los adultos y «recibirán los cuidados, la protección y toda la asistencia necesaria — social, educacional, profesional, sicológica, médica y física - que puedan requerir debido a su edad, sexo y personalidad y en interés de su desarrollo sano.» Junto a esto, se recomienda la coordinación entre las administraciones pertinentes para dar formación académica y/o profesional para que el menor no sufra desventaja a su salida respecto a su desarrollo educativo.

Tras estas reglas, la Asamblea General de las Naciones Unidas adoptó la Convención sobre los Derechos de la Infancia, Resolución 44/25 del 20 de noviembre al 1989, que al tratarse de un tratado vinculante, los estados miembros que se adhiriesen a esta convención, debían cumplir y adaptar su legislación a este marco normativo. De esta forma, España la ratificaría al año siguiente (BOE de 31 de diciembre de 1990). En esta convención destaca el carácter de menor de edad para aquellos jóvenes por debajo de los dieciocho años; que en todo momento prevalecerá el interés superior de éste y en su Artículo 40 determina, que para todo menor que se acuse o declare 
culpable de haber infringido la ley «se tenga en cuenta la edad del niño y la importancia de promover la reintegración del niño.» De la misma forma se establecerá una edad mínima bajo la cual se presume que el niño no puede infringir la ley, así como la disposición de una serie de alternativas previas al internamiento en instituciones específicas para garantizar la proporcionalidad entre la infracción y las circunstancias de éste.

Tras esta convención se formularán, las Directrices de las Naciones Unidas para la prevención de la delincuencia juvenil (Resolución 45/112) («Directrices de Riad») y las Reglas de las Naciones Unidas para la protección de menores privados de libertad (Resolución 45/113), de 14 de diciembre de 1990, en ambas resoluciones y al igual que ocurriese previamente con las Reglas de Beijing, se desarrollará específicamente el tratamiento de los menores privados de libertad y la delincuencia juvenil. En la primera de estas dos, se destaca la importancia de crear políticas que prevengan las actividades delictivas por parte de los jóvenes, haciendo hincapié en el análisis de estas conductas, la creación de mecanismos que la eviten y la importancia de la socialización de estos grupos. Para ello, centra su atención en el valor de la familia, la educación, la comunidad, los medios de comunicación y las políticas sociales que se realicen a tal efecto. Por último, destaca la importancia de desarrollar una legislación específica, la creación de la figura del mediador y la coordinación con otras áreas científicas en materia de investigación y estudio constante en esta materia.

Respecto a la segunda de las resoluciones, aparecen en ella algunas pautas con las que garantizar los derechos de los menores privados de libertad. Para ello, establece la importancia de respetar y velar por que se cumplan todo los derechos fundamentales para los menores que no puedan abandonar por su propia voluntad una institución, privados de libertad, tanto en cumplimiento de una medida judicial como en prisión preventiva. Junto a esto, enumera cómo debe ser la administración de los centros de menores, redactando las principales pautas a seguir en su funcionamiento.

Aquí, se comienza ya a definir cómo van a ser los centros de internamiento actuales y bajo qué políticas se van a regir. De esta manera, ya se formaliza la necesidad de crear un expediente personal y confidencial con toda la información del menor, cómo deben realizarse los ingresos, traslados o registros de éstos, el tratamiento individualizado, la obligación de desarrollar un plan de actuación detallado por parte de profesionales como psicólogos, médicos y maestros y las condiciones mínimas con las que deben contar las instalaciones dedicadas a tal efecto. 
Podemos ver como ésta es la primera norma a nivel internacional en la que se comienza a detallar cómo van a ser las instituciones objeto de nuestro estudio y en la que ya aparecen los primeros rasgos de nuestro análisis que serán posteriormente desarrollados por la legislación autonómica (donde la explicamos detalladamente). De esta forma, aquí también se dan las primeras instrucciones sobre educación, formación profesional, trabajo, actividades recreativas, religión, atención médica, contactos con la comunidad, limitaciones del uso de la fuerza y la coerción, inspecciones, procedimientos disciplinarios, personal y reintegración en la comunidad.

Esta legislación se completará con una serie de resoluciones posteriores en otras materias adyacentes con las que se tratará de dar una cobertura total a los menores de edad. Aunque no tocan de manera específica la materia de la delincuencia juvenil o el internamiento en centros de privación de libertad, sí que completan la funcionalidad de éstos y marcan los márgenes por donde deben desarrollarse y ampararse. Algunas de estas leyes pasamos a enumerarlas a continuación.

- Convenio sobre Competencia de Autoridades y Ley Aplicable en Materia de Protección de Menores. (La Haya, 5 de octubre de 1961).

- Convenio número 138 sobre la edad mínima de admisión al empleo (Ginebra, 26 de mayo de 1973).

- Declaración sobre los principios sociales y jurídicos relativos a la protección y el bienestar de los niños, con particular referencia a la adopción y la colocación en hogares de guarda, en los planos nacional e internacional. (Resolución 41/85 de la Asamblea General, de 3 de diciembre de 1986).

- Declaración y programa de acción de Viena, aprobados por la Conferencia Mundial de Derechos Humanos el 25 de junio de 1993, en su capítulo cuarto desarrolla y actualiza los derechos del niño.

- Convenio relativo a la Competencia, la Ley Aplicable, el Reconocimiento, la Ejecución y la Cooperación en materia de Responsabilidad Parental y de Medidas de Protección de los Niños (La Haya, 19 de octubre de 1996). Que España ratificará el 1 de abril de 2003.

- Declaración del Milenio aprobada por la Asamblea General de las Naciones Unidas, resolución 55/2, del 8 de septiembre del 2000 . 
- Protocolo facultativo de la Convención sobre Derechos del Niño relativo a la venta de niños, la prostitución infantil y la utilización de niños en la pornografía (25 de mayo del 2000).

- Protocolo facultativo de la convención sobre Derechos del Niño relativo a la participación de niños en los conflictos armados (25 de mayo del 2000).

- Protocolo para prevenir, reprimir y sancionar la trata de personas, especialmente mujeres y niños, que complementa la Convención de las Naciones Unidas contra la Delincuencia Organizada Transnacional. (Resolución 55/25 de la Asamblea General de las Naciones Unidas, de 15 de noviembre del 2000).

- Informe Final del Foro Mundial sobre la Educación, Dakar, del 26 al 28 de abril de 2000 .

- Sesión especial de la Asamblea General de las Naciones Unidas a favor de la Infancia, «Un mundo apropiado para los niños» (del 8 al 10 de mayo del 2002).

- Declaración de la reunión plenaria conmemorativa de alto nivel dedicada al seguimiento de los resultados del período extraordinario de sesiones sobre la infancia, de 13 de diciembre de 2007. Donde se recoge toda la información sobre las diferentes resoluciones de los últimos años sobre los derechos de los niños y las niñas.

- Protocolo facultativo de la convención sobre los Derechos del Niño relativo a un procedimiento de comunicaciones. Resolución aprobada por la Asamblea General de las Naciones Unidas el 19 de diciembre de 2011.

\section{MARCO EUROPEO}

Lógicamente, el desarrollo de todo el marco normativo procedente de las instituciones europeas se adaptará a las diferentes resoluciones internacionales, por lo que se han limitado a difundir estas directrices al mismo tiempo que creaban otras instrucciones específicas para su cumplimiento. De esta manera, y a modo de repaso general nos encontramos con las siguientes normas que influyen en la vida de los Centros de Internamiento y los menores infractores:

Recomendación (87) 21, adoptada por el comité de Ministros del Consejo de Europa, el 17 de septiembre de 1987 sobre la asistencia a las víctimas y la prevención de la victimización. Donde se incita a los 
diferentes estados miembros a investigar y prevenir la victimización de determinados grupos sociales o especialmente vulnerables.

Carta Europea de los Derechos del Niño. Aprobada por el Parlamento Europeo (DOCE n. ${ }^{\circ}$ C 241, de 21 de septiembre de 1992). En ella se enumeran todos los derechos del niño y destaca respecto a nuestro estudio como se especifica en el artículo 15, que siempre se tendrá por objeto prioritario la defensa y salvaguarda de sus intereses, en el artículo 17 el derecho a beneficiarse de todas las garantía de un proceso regular, de evitar una institución penitenciara para adultos en caso de ser declarado culpable y la implantación de un tratamiento adecuado con el objetivo de reeducarlo y encaminarlo hacia su posterior resocialización. De igual forma, menciona de manera específica algo crucial respecto a las diferencias socioeconómicas de los menores «la admisión de un niño en todo establecimiento que se beneficie de fondos públicos no podrá realizarse en función de la situación económica de sus padres, de sus orígenes sociales, raciones o étnicos, orientación sexual ni de sus creencias religiosas o no.» (Artículo 21 c.)

Carta de los Derechos Fundamentales de la Unión Europea (Niza, 18 de diciembre del 2000), cuyo artículo 24 desarrolla los derechos del menor.

El Libro Blanco de la Juventud Europea de 2002 (oficina de publicaciones oficiales de la Comunidad Europea, Luxemburgo, 2002). Donde se expone la necesidad de promover e impulsar la vida activa de la juventud europea como motor protagonista ante los tiempos venideros. La importancia de su participación, de la inclusión social; la importancia de la educación y la renovación de ésta así como la necesidad de una protección social específica.

Tratado por el que se establece una Constitución para Europa. (DOCE, n. ${ }^{\circ}$ C 310, de 16 de diciembre de 2004). Donde aparecen los Derechos del niño (Artículo II-84) y el interés superior de éste como consideración primordial en todos los asuntos públicos o privados.

Decisión n. ${ }^{\circ}$ 1719/2006/CE del Parlamento Europeo y del consejo de 15 de noviembre de 2006 por la que se establece el programa «la juventud en acción» para el período 2007-2013. Donde se redactan las propuestas para promover una ciudadanía europea para los jóvenes.

Decisión n. ${ }^{\circ}$ 779/2007/CE del Parlamento Europeo y del Consejo de 20 de junio de 2007 por la que se establece, para el período 20072013 , un programa específico para prevenir y combatir la violencia ejercida sobre los niños, los jóvenes y las mujeres y proteger a las víctimas y grupos de riesgo (programa Daphne III) integrado en el 
programa general «Derechos fundamentales y justicia.» Donde se indica como objetivo específico la prevención de toda forma de violencia y fija como uno de sus grupos destinatarios a los colectivos dedicado a la educación.

Además de ésta, aparece otra legislación, que si bien, no es específica sobre el internamiento o menores infractores, si completará el marco jurídico sobre éste. Así, encontramos diversas normas como la Carta Europea de los Niños Hospitalizados de 1986, las diferentes normas sobre la custodia de los menores, la regulación sobre el cibercrimen, la explotación sexual y la pornografía, recomendaciones sobre la mediación familiar, etc.

\section{MARCO ESPAÑOL}

Coincidiendo con lo que decíamos al comienzo del artículo sobre el Siglo de las Luces como punto de partida, remontándonos ahora en la legislación estatal en busca de los primeros indicios en materia de menores y realizando un bosquejo previo sobre la legislación que detalla específicamente la responsabilidad penal del menor en España, vemos como ya en los diferentes Códigos Penales de los dos últimos siglos $^{5}$ se les menciona y atribuye un mayor o menor peso, situándonos ahí como punto de partida en este análisis.

Siguiendo los apuntes de V. Sánchez (2002) y haciendo un recorrido general por estas leyes, vemos como el Código Penal de 1822 determina que, con los menores entre 7 y 17 años, una vez examinado si han realizado los hechos con malicia y discernimiento, habrá dos opciones: entregárselos a sus padres si eran dignos de confianza y respeto o ingresar en una casa de corrección (generalmente una cárcel común ya que éstas eran prácticamente inexistentes). En el Código Penal de 1848, se sitúa la edad mínima en los 9 años, aplicando a los menores con discernimiento una pena discrecional inferior en dos grados a la señalada por la ley para ese delito. En los

${ }^{5}$ Tal como decíamos antes, en paralelo a la legislación, se desarrollarán también los diferentes intentos de creación de centros independientes que nos llevarán a los centros de internamiento actuales. Así, podemos destacar la iniciativa de algunos directores de presidio que apostarán por la implantación de módulos exclusivos para menores, como el creado por el coronel Montesinos en Valencia (1835) e instituciones similares, como el Patronato de Niños y Adolescentes Abandonados y Presos en Barcelona (1880), creado por D. Ramón Albó, las escuelas especiales de Santa Rita (1875) en Madrid, el asilo Toribio Durán (1890) de Barcelona, el Centro de Reeducación de Menores en la cárcel de Córdoba (1910) creado por Juan Viso o la institución creada por los Terciarios Capuchinos (1890) en Dos Hermanas, Sevilla (Montero Pedrera, 2008). 
códigos de 1850 y 1870 se mantienen estos criterios aunque aparece la posibilidad de entregar a los menores inimputables (menores de 9 años o sin discernimiento de los hechos) a un establecimiento destinado al internamiento.

En 1904, Alfonso XIII firma la Ley Tolosa Latour, con la que se crea el Consejo Superior de Protección a la Infancia y Represión de la Mendicidad, que aunque se centra en aspectos relacionados con la puericultura y especialmente con la lactancia mercenaria, ya sienta algunas bases sobre la atención específica relacionada con los patronatos y el desarrollo jurídico-legislativo para menores de edad.

A partir de esta fecha y tras varios intentos de regulación abortados por la inestabilidad política de principio de siglo, saldrá adelante la Ley Montero Ríos (1918), que emanará directamente de ese espíritu infundado por la Children Court, que mencionábamos antes. Esta, junto a algunas personalidades que impulsarán el desarrollo de la materia legislativa hacía menores, como son D. Avelino Montero Ríos, D. Gabriel María de Ybarra o D. Ramón Albó, abrirán un periodo fértil de regulación sobre menores de edad. Junto a los Códigos Penales de 1928, 1932 y 1944, aparecerán las siguientes disposiciones específicas $^{6}$ :

— Ley de Bases de 2 de agosto de 1918 sobre organización y atribuciones de los Tribunales para niños.

— Ley de 25 de noviembre de 1918, sobre tribunales para niños.

- Reglamento provisional sobre organización y atribuciones de los Tribunales para niños. Real Decreto de 10 de julio de 1919.

- Reglamento definitivo sobre organización y atribuciones de los Tribunales para niños. Real Decreto de 6 de abril de 1922.

— Decreto-Ley de 15 de julio de 1925 sobre organización y atribuciones de los Tribunales Tutelares para niños.

- Reglamento provisional para ejecución de la Ley de Tribunales para niños de 15 de julio de 1925. Real decreto de 6 de septiembre de 1925.

- Nueva redacción de varios artículos del Decreto Ley y Reglamento de 1925. Real orden circular de 2 de abril de 1926 y Real orden de 14 de mayo de 1926.

${ }^{6}$ Seguimos para esta enumeración los apuntes de V. Sánchez (Sánchez Vázquez y Guijarro Granados, 2002: 131) 
— Real Decreto-Ley de 3 de febrero de 1929 sobre organización y atribuciones de los Tribunales Tutelares para niños.

- Reglamento provisional de Tribunales Tutelares de Menores. Real decreto de 3 de febrero de 1929.

— Decreto del 30 de junio de 1931 revisando la Ley y Reglamento de 1929.

— Ley de tribunales Tutelares de Menores de 1941.

- Decreto de 11 de junio de 1948 por el que se aprueba el texto refundido de la legislación sobre Tribunales Tutelares de Menores.

Partimos por tanto, de esta reforma de los Tribunales Tutelares de 1948 como referente hacia la situación actual. En este recorrido histórico por la diferente legislación sobre la responsabilidad penal de los menores, dentro del marco estatal y siguiendo las anotaciones del informe del defensor del menor de Andalucía (Maeztu Gregorio de Tejada, 2014: 23-44), vemos como la Ley de Tribunales Tutelares de Menores, aprobada por Decreto de 11 de Junio de 1948 atribuía el control de las infracciones a unos órganos de carácter provincial, denominados Tribuales Tutelares de Menores. Los agentes involucrados en estos procesos no eran técnicos sino que debían reunir únicamente un par de requisitos: ser mayores de 25 años y tener una vida «ejemplar». En esta ley, se trataba al menor como un sujeto irresponsable, actuando sobre él de manera proteccionista y con carácter paternalista, atribuyendo el control de sus infracciones a unos órganos de naturaleza administrativa.

Lógicamente, a partir de la Constitución Española de 1978, se puso de manifiesto la necesidad de reformar esta legislación, aunque no sería hasta la Sentencia n. ${ }^{\circ}$ 36/1991, de 14 de febrero, cuando se declarase inconstitucional el artículo 15 de la Ley de Tribunales Tutelares de Menores, abriendo la puerta a su reforma y adecuación al marco legislativo internacional, al modelo educativo-responsabilizador, amparado por las normas de Beijing que explicamos más adelante.

De esta forma, se abre un periodo en el que hay un vacío legislativo donde serán los propios jueces quienes utilicen unos procedimientos adaptados a los dictados del Tribunal Constitucional, los preceptos de la Constitución y la Convención de los Derechos de Niño para dictar sentencia.

Esta situación se clarificará con la Ley Orgánica 4/1992, de 5 de junio, Reguladora de la Competencia y el Procedimiento de los Juzgados de Menores. Se trata de una norma de carácter urgente en la 
que se establece un marco flexible por el que los Juzgados de Menores podían establecer las medidas aplicables sobre los hechos tipificados como infracciones penales y siempre prevaleciendo el interés del menor.

Esta normativa de carácter provisional, evidenciará sus carencias con la entrada en vigor del Código Penal aprobado por la Ley Orgánica 10/1995 de 23 de noviembre, principalmente en lo relativo al establecimiento de la mayoría de edad. Por lo que, finalmente, acabará desembocando en una legislación específica donde se aseguraran todas las garantías procesales penales de la personas menores, acordes al marco legislativo e histórico actual. Esto ocurrirá con la Ley Orgánica 5/2000, de 12 de enero, de Responsabilidad Penal de Menores (en adelante LORPM), cuya entrada en vigor se retrasó hasta enero de 2001.

Esta será la primera norma específica sobre responsabilidad penal del menor de carácter estatal, donde, tal como dice en su exposición de motivos, en el artículo 3, se describirán todas las «exigencias de responsabilidad para los jóvenes infractores que no hayan alcanzado la mayoría de edad penal, fundamentada en principios orientados hacia la reeducación (...)» y teniendo siempre presente el interés superior del menor. Si la analizamos brevemente, podemos observar algunos de los elementos claves que caracterizarán la actuación con menores infractores hoy en día.

Ya en la exposición de motivos y el título preliminar, donde se justifica su redacción, su ubicación dentro del marco europeo e internacional (que antes hemos mencionado) y las pertinentes modificaciones, nos apunta como esta ley está encaminada al desarrollo de la responsabilidad jurídica de los menores y de sus personalidades. Buscando la consecución de los siguientes objetivos: responsabilizar al joven en relación al delito cometido, orientarlo hacia un proceso normalizado de resocialización, fomentar nuevos aprendizajes que tiendan al desarrollo personal y social y compensar las carencias y necesidades del menor, respetando el proceso evolutivo de cada uno de ellos.

Ésta se basa, como principios generales,

en la naturaleza formalmente penal, pero materialmente sancionadora educativa del procedimiento y de las medidas aplicables a los infractores menores de edad, reconocimiento expreso de todas la garantías que se derivan del respeto de los derechos constitucionales y de las especiales exigencias del interés del menor, diferenciación de diversos tramos a efectos procesales y sancionadores en la categoría de infractores menores de edad, flexibilidad en la adopción y ejecución de las 
medidas aconsejadas por las circunstancias del caso concreto, competencia de las entidades autonómicas relacionadas con la reforma y protección de menores para la ejecución de las medidas impuestas en la sentencia y control judicial de esta ejecución. (LORPM. Artículo 6. Capítulo 2).

De la misma forma y respecto al internamiento dice que las medidas responderán a una mayor gravedad de los hechos cometidos, caracterizados principalmente por la violencia, la intimidación o el peligro de las personas;

el objetivo prioritario de la medida es disponer de un ambiente que provea de las condiciones educativas adecuadas para que el menor pueda reorientar aquellas disposiciones o deficiencias que han caracterizado su comportamiento antisocial, cuando para ello sea necesario, al menos de manera temporal, asegurar la estancia del infractor en un régimen físicamente restrictivo de su libertad. La mayor o menor intensidad de tal restricción da lugar a los diversos tipos de internamiento (...) (LORPM. Artículo 7).

Si continuamos avanzando por esta ley, vemos como en su artículo primero, dentro del Título Preliminar, aclara que sus destinatarios serán los menores, catalogados así como aquellos con edades comprendidas entre catorce y dieciocho años y los jóvenes, refiriéndose a aquellos con edades comprendidas entre dieciocho y veintiún años; que hayan cometido algún hecho tipificado como delito o faltas, establecidos en el Código Penal o las leyes especiales. Aquí también se aclara que se referirá a todo este colectivo como menores en general, incluyendo tanto a menores de dieciocho años como a los jóvenes menores de veintiuno. Esto, sin embargo, será derogado en la modificación realizada en 2006, quedando establecidos el objeto de aplicación de esta ley tan solo a los menores de 18 años, y a los mayores de 18 años que se les seguirá aplicando durante el cumplimiento de su medida sancionadora educativa.

Si realizamos un somero repaso de sus contenidos siguiendo su estructura, vemos como en el Título I, sobre el ámbito de aplicación define la competencia del juez, del ministerio fiscal y la edad del menor y del joven que mencionábamos antes. Destacando como serán incluidos estos jóvenes mayores de dieciocho dentro de la ley del menor siempre que reúnan estos requisitos: que se trate de delitos menos graves (sin violencia ni intimidación), sujetos que no hayan sido condenados por hechos delictivos una vez han cumplido los dieciocho años y que así se recomiende por el equipo técnico.

En el Título II, sobre las medidas, lo más destacable es la descripción que se realiza de los diferentes tipos de medidas que pueden ser 
impuestas al menor. Que presenta un continuum en función de la gravedad de los hechos cometidos. De esta forma, de manera enumerada serían las siguientes:

Régimen cerrado. Los menores residen en el centro y realizan en él todas las actividades formativas, laborales y de convivencia.

Régimen Semiabierto. Los menores residen en él pero realizan fuera del centro las actividades formativas, laborales y/o de ocio.

Régimen Abierto. Los menores utilizarán el centro como domicilio habitual, realizando todas las actividades en su entorno.

Medida de internamiento terapéutico. Los menores residirán en centros con una atención educativa especializada y un tratamiento específico.

Tratamiento ambulatorio. Los menores tendrán que asistir con la periodicidad requerida a un centro donde los facultativos le establecerán unas pautas con las que se trate las anomalías o problemas de adicción, alteración psíquica o de percepción que padezcan.

Asistencia a centro de día. Los menores residirán en su domicilio y asistirán a este centro a realizar tareas de apoyo.

Permanencia de fin de semana. Los menores permanecerán en un centro de internamiento o en su domicilio durante un periodo de 36 horas durante un número de veces establecido.

Libertad Vigilada. Los menores tendrán un seguimiento de sus actividades y una revisión de éstas durante el tiempo establecido.

Convivencia. El menor tendrá que convivir con otras personas o familias distintas a las suyas y seguir un programa educativo.

Prestación en beneficio a la comunidad. El menor, que deberá aceptarlas voluntariamente, realizará actividades no remuneradas de interés social o en beneficio de personas en precariedad.

Tareas socioeducativas, amonestación o privación del permiso de conducción. Actividades específicas de carácter educativo, reprensiones por parte del juez para que comprenda la gravedad de los hechos o la privación del uso del ciclomotor o automóvil, si la falta se ha cometido con el empleo de estos, serán otras de las medidas posibles a imponer a los menores.

Como vemos, serán las cuatro primeras medidas, las que encontraremos en los centros de internamiento, pudiéndose complementar 
entre ellas y con las siguientes. De manera que en los centros de internamiento podremos tener menores con medidas de cerrado que se conviertan en el transcurso de su cumplimiento en medidas de semiabierto o abierto, o alguna de éstas compaginadas con una medida de terapéutico, prestación de bienes a la comunidad, tratamiento ambulatorio o que desemboquen en la libertad vigilada

Para tener una idea a priori, basada en esta legislación, generalmente, tal como dice el Artículo 9 el régimen cerrado se aplicará en el caso de actos violentos o intimidación con una duración máxima de dos años, aunque, excepcionalmente, se podrán imponer medidas de uno a cinco años en régimen cerrado, cuando los supuestos previstos en esta ley revistan una extrema gravedad.

Respecto a la imposición de varias medidas, el concurso de infracciones o la infracción continuada, siempre se actuará siguiendo el principio de la más grave, respecto a la pluralidad de actos o víctimas, así como su cumplimiento.

Continuando con el análisis de esta ley, crucial en la atención a los menores infractores, vemos como en el Título III, el Capítulo I, trata sobre la instrucción del procedimiento, por lo que no atañe de manera directa a nuestro estudio. En él, se nos dan las claves sobre el proceso de incoación del expediente, la detención de menor (que tendrá que ser informada y llevada a cabo de la manera que menos perjudique a éste), sobre el desistimiento, sobreseimiento, incoación del expediente, etc. Destaca también, en su Artículo 27, como se deberá realizar un informe por parte Equipo Técnico en el que se establezcan las pautas de actuación y el perfil del menor.

Ya en el Capítulo II, nos habla sobre las medidas cautelares y el Capítulo III, sobre la conclusión y remisión del expediente al juez.

En el Título IV, V y VI se describe la fase de audiencia, la sentencia y el régimen de recursos, por lo que no influirá de manera directa en nuestro estudio sobre el internamiento.

En el titulo VII, de la ejecución de las medidas, tanto el Capítulo I como el Capítulo II, nos describe como, una vez sentenciado, el menor debe trasladarse al centro donde cumplirá la medida, como debe realizarse el traslado, la ejecución de varias medidas (que se refundirán), la realización de un expediente personal del menor, al que solo tendrá acceso el Defensor del Pueblo, jueces, fiscalía, autorizados de la entidad que administra el centro, menor y abogado autorizado por éste, los informes sobre la ejecución donde se muestre el progreso y 
evolución del menor en el cumplimiento de su medida y los pasos a seguir en caso de quebrantamiento de la ejecución de la medida, sustitución de ésta o presentación de recursos.

Por último, dentro del Título VII, en el Capítulo III sobre las reglas especiales para la ejecución de las medidas, se nos indican algunas pautas sobre cómo van a ser los centros y su funcionamiento. Comienza con el Artículo 54, donde se describen los centros para la ejecución de las medidas.

Será en este artículo donde se establezcan las definiciones básicas sobre el perfil de los centros de internamiento y la actuación que se lleve a cabo en ellos, por lo que pasamos a describir lo que en él se recoge.

Aquí se específica que los centros serán diferentes de los previstos para la ejecución de medidas privativas de libertad a mayores de edad penal.

Estos, tendrán que estar divididos en módulos adecuados a la edad, madurez y necesidades de los menores. Respondiendo a una normativa interna que promueva la convivencia ordenada y que permita la ejecución de los programas de intervención educativa.

En el Artículo 55, se nos vuelve a remarcar que el fin último de los centros es el principio de resocialización, por lo que se deberá tomar como referencia la vida en libertad, reduciendo al máximo los efectos negativos del internamiento y favoreciendo el proceso de integración social.

En los siguientes artículos se nos presentan los derechos y deberes de los menores internados. En estos dos artículos, se remarca como el interno tiene derecho a su propia personalidad, libertad religiosa e ideológica y en general todos aquellos no afectados por su condena. De forma específica destaca el derecho a que el centro vele por su vida e integridad física, a recibir educación y asistencia sanitaria gratuita y a recibir un tratamiento individualizado para hacer efectivo su desarrollo.

De la misma manera, el menor internado tiene el deber de cumplir las normas de funcionamiento interno, colaborar en las actividades, utilizar adecuadamente las instalaciones, observar las normas de higiene y sanidad y permanecer en el centro a disposición de la autoridad judicial.

Siguiendo con este Capítulo III, el Artículo 59 menciona cómo serán las medidas de vigilancia y seguridad, en las que se especifica 
que se podrán realizar registros en las dependencias y enseres y se podrán utilizar los medios de contención establecidos reglamentariamente para evitar actos de violencia o lesiones, actos de fuga, daños a las instalaciones o resistencia a las instrucciones del personal.

En el Artículo 60 se establece que todos los centros de internamiento contarán con un régimen disciplinario que clasificará las faltas en muy graves, graves y leves, atendiendo a la violencia desarrollada por el sujeto. Estas acarrearán la separación del grupo (por días o fines de semana), la privación de salidas o la participación en las actividades recreativas.

Ya en el Título VIII, el último de esta ley, se desarrolla todo lo relativo a la responsabilidad civil. En los artículos 61, 62, 63 y 64 se establecerán el procedimiento y las reglas generales para esto.

Por último, en las disposiciones adicionales, transitorias y finales, destaca la especialización en esta materia por parte de los miembros de la Carrera Judicial y Fiscal así como la creación de una Sección de Menores en todas las Fiscalías y la progresiva formación específica en los colegios de letrados.

Esta norma será desarrollada por el Real Decreto 1774/2004, de 30 de julio, por el que se aprueba el Reglamento de la LORPM (BOE núm. 209 de 30 de agosto de 2004) donde se regula la actuación de la policía judicial y el Equipo Técnico, la ejecución de medidas y el régimen disciplinario de los centros. Este último, debatido y criticado por su paralelismo con la Ley Orgánica General Penitenciaria.

Esta Ley Orgánica, será modificada antes de su entrada en vigor en un par de ocasiones. A través de la Ley Orgánica 7/2000, de 22 de diciembre, con la que se definían los delitos de terrorismo y se incluía un nuevo delito denominado urbano, callejero o impropio, en el que eran frecuente la participación de menores (kale borroka), endureciendo las penas para estas acciones; y por otro lado la Ley Orgánica 9/2000, de 22 de diciembre, en la que se efectuaba una modificación respecto a la posibilidad de aplicar la ley de menores a jóvenes en edades entre los 18 y 20 años siempre que se tratara de un delito menos grave o falta en la que no hubiera concurrido violencia o intimidación, ni grave riesgo para la vida o integridad de las personas.

Finalmente, la última reforma legislativa se realizó con la Ley Orgánica 8/2006, de 4 de diciembre, donde se adecúa la ley sobre responsabilidad penal del menor del 2000 a las directrices de la modificación del Código Penal realizados en la Ley 15/2003, de 25 de noviembre; por la que se debían ajustar la prolongación del tiempo de internamiento, 
el establecimiento del cumplimiento de las medidas impuestas en centros de seguridad reforzada y el cumplimiento de la medida judicial cuando el menor hubiese cumplido la mayoría de edad.

Lo más destacable de esta modificación, junto a la limitación de la edad a 18 años tal como decíamos más arriba, será que, debido a la sensibilización social por el aumento de delitos cometidos por menores y el descrédito en la ley que esto ha producido y, aunque sigue primando el interés del menor, se deja a manos del juzgador la posibilidad de una mayor proporcionalidad entre la respuesta sancionadora y la gravedad del hecho.

Aunque reconoce que no han aumentado los delitos de carácter violentos, los acontecidos han tenido un fuerte impacto social, por lo que se ha tomado la directriz de endurecer sólo aquellas acciones que revisten especial gravedad.

\section{MARCO AUTONÓMICO}

A nivel andaluz son varias las normas que se han formulado a partir de la LORPM y con las que se desarrolla esta Ley Orgánica, perfilando las funciones de los diferentes colectivos participantes o regulando su actuación en los centros de internamiento de menores infractores.

Encontramos la Resoluciones de 1 a 7-2007-SMI de 4 de diciembre de 2007 de la Dirección General de Reforma Juvenil, y sus respectivos anexos, sobre ejecución de medidas privativas de libertad en Centros de Internamiento de Menores Infractores. En estas resoluciones se dictan las normas sobre cómo será la organización y gestión de servicios en los centros de internamiento. Dando unas directrices sobre la finalidad de éstos y el enfoque que deben tener las medidas de los menores, siempre amparadas por ese espíritu de resocialización y desarrollo personal de éste.

En estas resoluciones también aparecen aspectos como la vigilancia y el control de los menores; que será responsabilidad de los trabajadores. De esta forma, también reconoce esta norma, que podrá existir un personal especializado que velará por la seguridad del centro, desempeñando funciones de vigilancia y apoyo a las labores del personal aunque siempre dependerá de la dirección del centro. Estas resoluciones irán también acompañadas de algunas circulares, con las que detallar los procedimientos de actuación respecto a los usuarios del programa informático de administración (intr@) y gestiones similares (Circular 1-2007-SMI o Circular 1-2008-SMI). 
Tras éstas, la Resolución 1-2008-SMI, de 21 de abril, de la Dirección General de Justicia Juvenil, y su modificación del 30/06/2008, dará las prescripciones sobre el sistema general de centros, elaboración de informes y ejecución de medidas privativas de libertad. La actuación profesional en los centros se continuará perfilando a través de las sucesivas resoluciones, como la 1-2012-SMI, de 12 de enero de 2012 con la que se describirán cómo serán los informes realizados respecto a la ejecución de medidas.

También contaremos con el Decreto 33/2008, de 5 de febrero, por el que se regulan los centros y servicios de reforma juvenil y se establece el sistema de gestión de la calidad. Aquí se definen los distintos tipos de centros de reforma que existen en Andalucía y donde ya aparece en su artículo segundo la definición de Centros de Internamiento de Menores Infractores, como aquellos «centros destinados a residencia de menores a los que se le ha impuesto una medida judicial privativa de libertad y, donde estos realizan, en todo o en parte, los programas de intervención y las actividades educativas, formativas, laborales y de ocio.»

En estos centros se actuará ateniéndose a los criterios generales de la efectiva integración social de los menores y jóvenes, al mismo tiempo que respetando y defendiendo los derechos del ordenamiento jurídico vigente.

Finalmente, toda esta legislación desembocará en el Decreto 98/2015, de 3 de marzo, por el que se regula la organización, funcionamiento y características de los Centros de Internamiento de Menores Infractores de Andalucía y se crea la Comisión Andaluza de Centros de Internamiento de Menores Infractores.

Junto a la LORPM, constituyen las dos grandes normativas por las que se rigen los Centros de Internamiento. De esta forma, la LORPM constituye el gran marco a partir del que se desarrolla toda la legislación posterior sobre el menor infractor, mientras que este Decreto, de creación reciente, formaliza y consolida el funcionamiento y las pautas de actuación tanto de los Centros de Internamiento como de sus protagonistas.

En este decreto, de manera destacable para nuestro estudio, aparece:

La estructura organizativa y funciones de los miembros de los centros. Éstos, estarán compuestos por dirección y subdirección como órganos unipersonales, encargados de dirigir, coordinar, supervisar toda la actividad del centro, así como ejercer la guarda de 
las personas internas menores de edad y autorizar las salidas y procedimientos disciplinarios. El equipo socioeducativo encargado de la intervención integral con el interno, compuesto por profesionales del ámbito de la psicología, trabajo social, derecho, sanidad, educadores y monitores de talleres. Las comisiones socioeducativas, entendidas estas como órganos multidisciplinares donde se elaboran, evalúan y propone todo lo relacionado a la intervención con los menores internos y que estarán compuestas por dirección, psicólogos, trabajadores sociales, coordinadores, educadores/tutores del menor y profesionales del derecho. Y por último, el personal de administración y servicios y personal de vigilancia.

Junto a esta estructura interna de los CIMI, aparecerá también la comisión técnica como el órgano que decidirá las pautas para la planificación y programación de la actividad socioeducativa que se desarrollará en los centros Ésta estará compuesta por miembros del centro, como son la dirección y subdirección, a la vez que por miembros externos, como son las personas titulares de la jefatura de servicio con competencia en la materia del órgano territorial de la Administración de la Junta de Andalucía de la provincia y otra designada por la presidencia, que preste servicio en dicho órgano.

En su Capítulo II, dicta las normas de funcionamiento, donde se establecerán todas las pautas de actuación de los CIMI y el marco bajo el que deben desenvolverse. Así, en los artículos que van desde el 19 al 33, nos enumera:

Documentos técnicos. El CIMI debe constar con un Proyecto Educativo de Centro, un Plan Anual de Actividades, una Memoria Anual y un libro de registros, donde quede plasmada toda la actividad anual y diaria de éstos.

La intervención en éstos. El conjunto de actuaciones, principalmente socioeducativas, que se llevarán a cabo en los centros, atendiendo a los principios de individualización, globalización, responsabilidad, equidad y autonomía de los menores, con el objetivo de garantizar los principios de la LORPM y posibilitando el desarrollo y la integración de los menores internos.

Las Fases Educativas. Las diferentes etapas por las que pasará el menor interno y que marcarán toda la vida en el centro. Estas son:

Fase de observación. En la que el menor necesita control para la adaptación a la vida del centro, por ser de nuevo ingreso o haber retrocedido en su progreso. 
Fase de desarrollo. Donde se desarrolla una intervención global caminando progresivamente hacia su autonomía.

Fase de consolidación. En la que se prepara al menor para la reincorporación a su entorno sociofamiliar.

Los Contenidos de la Intervención, que además de los programas generales, se crearán otros específicos con los que tratar delitos violentos, sexuales, violencia filioparental, prevención y tratamiento de las drogodependencias, atención a la población extranjera, madres y padres adolescentes y programas para madres con hijos a su cargo.

Por último se dan las pautas para la ejecución de las medidas, adjudicación del centro, ingreso, creación de un expediente único y la baja del menor una vez haya sido puesto en libertad, trasladado a otro centro o fallecido.

Ya en su Capítulo IV, describe las características de los centros de internamiento. Otro de los elementos clave en nuestro estudio. Así, nos dice esta ley que los CIMI deberán cumplir una funcionalidad acorde con las actuaciones socioeducativas programadas y la legislación referente vigente. Deberán estar dotados de las medidas de protección y seguridad exigidas, especialmente contra incendios así como también contará con un plan de autoprotección, siguiendo la Norma Básica de Autoprotección incluida en el Real Decreto 393/2007, de 23 de marzo, en el que se incide en las situaciones de emergencia que se pudiesen dar en estos entornos.

Respecto a las zonas del centro, dicta esta norma que deberá distinguirse entre las zonas de profesionales, servicios, zona residencial, formativos y de tiempo libre. También deberá haber una estancia dedicada específicamente a las comunicaciones y visitas y otras en las que los registros o las medidas de contención que se empleen, cuenten con medios técnicos de manera que se realicen de la manera «menos gravosa» para el menor.

Por último, en el Capítulo V define la supervisión y control de los centros de internamiento, que correrá a cargo de la consejería con competencia en materia de justicia juvenil y el personal técnico dependiente de ésta.

A lo largo de esta norma se establecen las actuaciones tanto para los centros gestionados de forma directa por la administración como los gestionados de forma indirecta, que en líneas generales coincidirán en sus pautas de actuación. 
Finalmente, este decreto propone la creación de la Comisión Andaluza de Centros de Internamiento de Menores Infractores como órgano de coordinación y asesoramiento, con el que elaborar y efectuar propuestas sobre las pautas de actuación en éstos así como realizar estudios y análisis sobre el desarrollo normativo y la ejecución de medidas.

\section{ALGUNAS CONCLUSIONES}

Siguiendo toda esta normativa, se nos hace fácil comenzar a fraguar una imagen de cómo es la composición de los Centros de Internamiento de Menores Infractores en Andalucía y como quedan enmarcados dentro del gran puzle legislativo tanto desde una perspectiva histórica como estructural.

Con este recorrido, queda reflejada desde el principio hasta la más reciente, toda la legislación referente que, desde el marco jurídico, nos dicta el origen, funcionamiento, pautas de actuación y composición de estos centros de internamiento, así como la actuación con los menores infractores y las medidas privativas de libertad.

De esta manera vemos como estas instituciones continúan progresando hacia unos espacios propios, cada vez más independientes de otras instituciones de adultos que, aunque aparentemente similares, comienzan a ser totalmente diferentes, en cuanto a la forma y a la función que desempeñan.

\section{BIBLIOGRAFÍA}

CÁmara Arroyo, S. (2010) «La finalidad educativa de los Centros de Internamiento de Menores: el Hospicio como antecedente.», Anuario Facultad de Derecho - Universidad de Alcalá III, pp. 521-554.

FERNÁNDEZ EsCorial, M. (2006) «Aproximación a la Historia de las Prisiones. El caso de Málaga.», in Cruces, E. and Aquesolo, J. Los años convulsos. 1931-1945. Documentación del Archivo Histórico Provincial de Málaga., Cádiz.: Junta de Andalucía. Consejeria de Cultura.

García VAldes, C. (1997) Historia de la Prisión: teoría economicista, crítica: (curso de Doctorado), Madrid: Edisofer.

MAeztu GRegorio de TejadA, J. (2014). Informe especial: la atención a menores infractores en Centros de Internamiento en Andalucía. Sevilla, Defensor del menor de Andalucía. 
Monge González, A. (1997) «La pena de muerte en Europa», in García Valdes, C. Historia de la Prisión: teoría economicista, crítica: (curso de Doctorado), Madrid: Edisofer.

Montero Pedrera, A.M. (2008) «Luis Amigó y Ferrer, Los terciarios capuchinos y la protección de menores.», Escuela Abierta, pp. 167189.

RoldÁn BARBERo, H. (1988) Historia de la prisión en España, Barcelona: Instituto de Criminología.

SÁnchez VÁzouez, V. y Guijarro Granados, T. (2002) «Apuntes para una historia de las instituciones de menores en España.», Revista Asociacion Española de Neuropsiquiatría, vol. XXII, no. 84, pp. 121-138. 